Supporting Information

\title{
A Multifunctional Nanohybrid of Alumina and Indium Oxide Prepared Using Atomic Layer Deposition Technique
}

Le Thai Duy, ${ }^{\dagger}$ Hyunwoo Kang,,$"$ Hee-cheol Shin, Seunggik Han, ${ }^{\dagger}$ Ranveer Singh, ${ }^{\dagger}$

Hyungtak Seo $o^{\dagger, t * *}$

$\dagger$ Department of Materials Science and Engineering, Ajou University, Suwon, 16499, Republic of Korea.

‡ Department of Energy Systems Research, Ajou University, Suwon, 16499, Republic of Korea.

* Corresponding Email: hseo@ajou.ac.kr

KEYWORDS. indium oxide, aluminum oxide, atomic layer deposition, TCO, sensing 

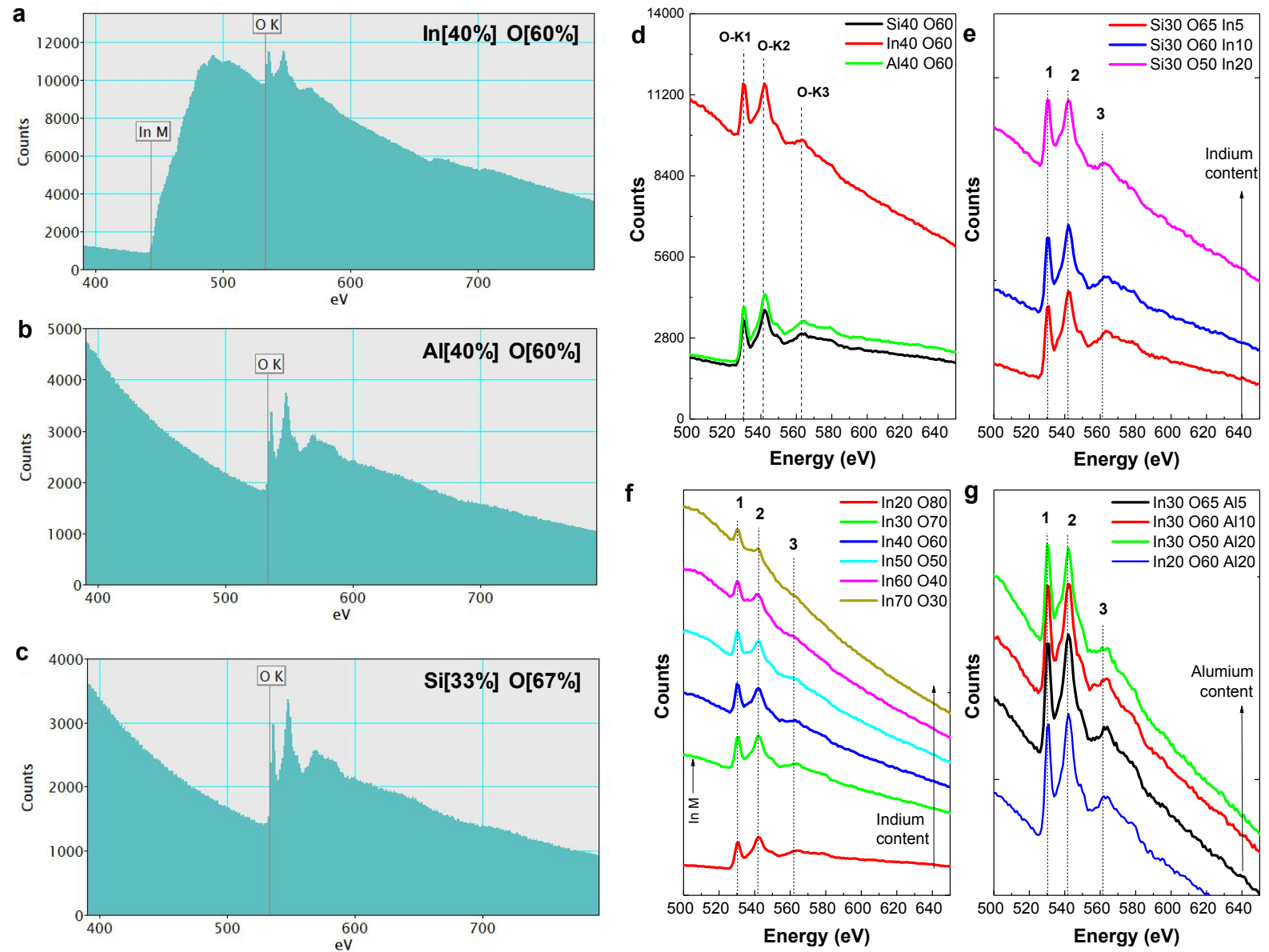

Figure S1. TEM-EELS simulation*. (a-c) Simulated EELS spectra of $\operatorname{In}_{2} \mathrm{O}_{3}(\mathrm{I} / \mathrm{O}$ ratio $=40 / 60)$, $\mathrm{Al}_{2} \mathrm{O}_{3}(\mathrm{Al} / \mathrm{O}$ ratio $=40 / 60)$, and $\mathrm{SiO}_{2}(\mathrm{Si} / \mathrm{O}$ ratio $=33 / 67)$, respectively, in the energy range of $400 \sim 800 \mathrm{eV}$. Here, these spectra and the later ones were obtained using "EELS Advisor" package in GATAN microscopy suite software (ver. 3.43, with a free license of "SI Viewer"); the sample thickness was fixed at $15 \mathrm{~nm}$; the settings for simulation adopted "EELS Atlas" model for determining core-loss of all elements while those for experimental conditions and optimization were kept defaults. (d) Comparison of the O-K edge spectra of those oxide (from (a-c)). (e-g) Changes in the $\mathrm{O}-\mathrm{K}$ spectra due to the component variation (element content) of mixed $\mathrm{Si}+\mathrm{In}$ oxides (i.e., $\mathrm{IO} / \mathrm{SiO}_{2}$ interface), In oxides (i.e., IO layer), and mixed $\mathrm{Al}+\mathrm{In}$ oxides (i.e., $\mathrm{AO} / \mathrm{I}$ ) interface), respectively.

* It is worth noting that the accuracy of simulated positions of the O-K edge and component peaks is not perfect if using only GATAN's default settings due to the dissimilar binding energy between oxygen with different metal elements; indeed, that needs complicated simulations and correlations for improving the accuracy. However, these fundamental calculations are sufficient for us to withdraw important evidences - changes in the ratios of component peaks and the level 
of spectrum background of different compositions - for understanding the changes in the measured EELS data in Figure 1f.

Briefly, Figure S1d shows not only a similarity in the O-K1/O-K2 ratio of insulating $\mathrm{SiO}_{2}$ and $\mathrm{Al}_{2} \mathrm{O}_{3}$ but also a spectrum-level difference between these insulating oxides with electroconductive $\mathrm{In}_{2} \mathrm{O}_{3}$. That level difference originated from the overlapping of In-M peak with $\mathrm{O}-\mathrm{K}$ peak (evidenced in Figure S1a-c). Furthermore, Figure S1e,f shows the proportional relationship between the In content and the O-K1/O-K2 ratio in the In+Si oxide film and the In oxide film. Here, once again, we observed that the increases in the In content made their background level significantly raising. This look similar to the EELS profiles $5^{\text {th }} \sim 13^{\text {th }}$ in Figure 1f. Besides, the $\mathrm{O}-\mathrm{K} 1 / \mathrm{O}-\mathrm{K} 2$ ratio of profiles $9^{\text {th }} \sim 10^{\text {th }}$ is more than 1 , indicating the very low oxygen content in the middle of the IO layer, as comparing to Figure S1f. Finally, Figure S1g shows two opposite effects of the Al content increases: (i) if the Al content increases by replacing the $\mathrm{O}$ content, the $\mathrm{O}-\mathrm{K} 1 / \mathrm{O}-\mathrm{K} 2$ ratio increases; (ii) if the increase of $\mathrm{Al}$ content comes along with a decrease in the In content, the O-K1/O-K2 ratio decreases. In other words, changes of the O$\mathrm{K} 1 / \mathrm{O}-\mathrm{K} 2$ ratio would be proportional to the metallic atom content and opposite to the oxygen content in the oxide film. These are important clues to confirm the interfaces between oxide layers in Figure 1f and explain which layer is electrical conducting.

In summary, these simulated results disclosed some important points, such as:

- The appearance of indium oxide, along with the In-M peak, raises the spectrum background level at below $520 \mathrm{eV}$.

- The increases of the O-K1/O-K2 peak ratio reflect the content of indium in the oxide layers.

- The increase of In, as well as the decrease of $\mathrm{O}$, also denotes the conductivity level of the indium oxide layer as a result of raising of oxygen vacancy. In this scenario, it suggests that the middle part of IO layer owns a higher electrical conductivity (profiles $7^{\text {th }} \sim 12^{\text {th }}$ in Figure 1f) than the $\mathrm{AO} / \mathrm{IO}$ interface (profiles $5^{\text {th }} \sim 6^{\text {th }}$ ) or the $\mathrm{IO} / \mathrm{SiO}_{2}$ interface (since profile $12^{\text {th }}$ ). 

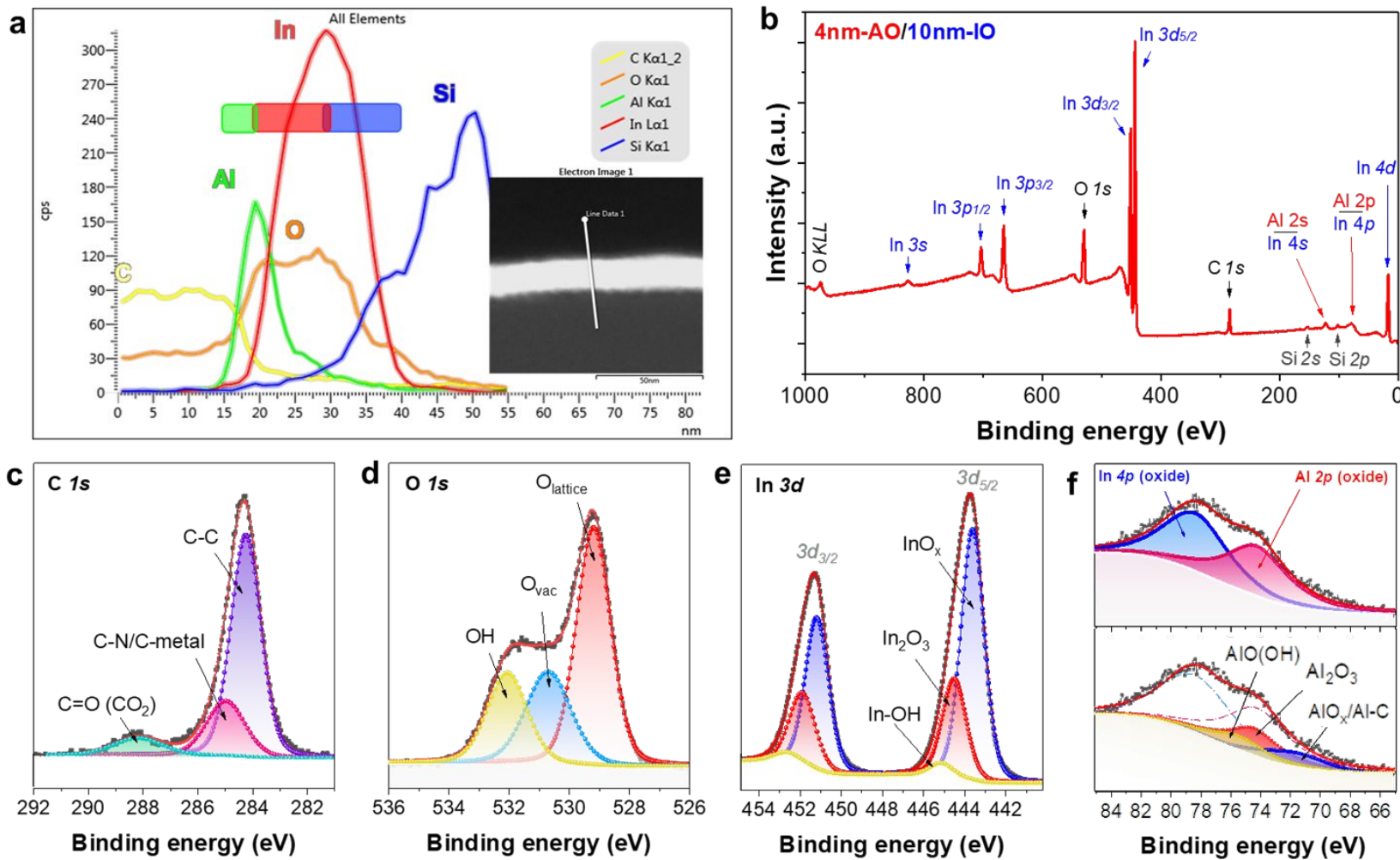

Figure S2. Nanohybrid characterization. (a) TEM-EELS elemental profile of 4nm-AO/10nmIO/glass; the inset cross-sectional image shows the scanning profile line. Here, the existence of a tiny carbon amount at a depth between 15 20 mm suggests the insignificant residue of unreacted AO's precursor (TMA). (b) XPS survey of that AO/IO sample. (c,d,e) XPS narrow survey and deconvolution of $\mathrm{C} 1 s, \mathrm{O} 1 s$, and In $3 d$ orbitals, respectively.1-9 (f) XPS survey of Al $2 p$ orbital; here, the top plot showed the overlap of the Al $2 p$ and In $4 p$ peaks, and the bottom plot showed the deconvolution of Al 2p. ${ }^{10-13}$ Here, Gaussian-Lorentz function (80-20) was applied to fitting.

The fitting results in Figure S2d,e reveal the significant portion of oxygen vacancies in the nanohybrid layer. That in Figure S2f shows significant amounts of O-Al-OH and $\mathrm{AlO}_{\mathrm{x}} / \mathrm{Al}-\mathrm{C}$ binding energies, indicating that an incomplete reduction of $\mathrm{AO}^{`} \mathrm{~s}$ precursor after a short ALD process time.

\section{References}

(1) Kannan SK, Thirnavukkarasu P, Jayaprakash R, Chandrasekaran J, Mohanraj V. Transition of nanocrystalline $\operatorname{In}(\mathrm{OH}) 3$ as spherical Indium Oxide nanoparticles embedded platelets. Mater Sci Semicond Process 2016;50:31-5. https://doi.org/10.1016/J.MSSP.2016.04.010.

(2) Kyndiah A, Ablat A, Guyot-Reeb S, Schultz T, Zu F, Koch N, et al. A Multifunctional Interlayer for Solution Processed High Performance Indium Oxide Transistors. Sci Reports 201881 2018;8:1-7. https://doi.org/10.1038/s41598-018-29220-0.

(3) Wang M, Wang C, Tian Y, Zhang J, Guo C, Zhang X, et al. Study on optical and electric properties of ultrafine-grained indium films. Appl Surf Sci 2014;296:209-13. https://doi.org/10.1016/j.apsusc.2014.01.093. 
(4) Loh JYY, Kherani NP. X-ray photospectroscopy and electronic studies of reactor parameters on photocatalytic hydrogenation of carbon dioxide by defect-laden indium oxide hydroxide nanorods. Molecules 2019;24. https://doi.org/10.3390/molecules24213818.

(5) Dang MT, Lefebvre J, Wuest JD. Recycling Indium Tin Oxide (ITO) Electrodes Used in Thin-Film Devices with Adjacent Hole-Transport Layers of Metal Oxides. ACS Sustain Chem Eng 2015;3:3373-81. https://doi.org/10.1021/ACSSUSCHEMENG.5B01080.

(6) Han JH, Jung EA, Kim HY, Kim DH, Park BK, Park JS, et al. Atomic layer deposition of indium oxide thin film from a liquid indium complex containing 1-dimethylamino-2-methyl-2-propoxy ligands. Appl Surf Sci 2016;383:1-8. https://doi.org/10.1016/J.APSUSC.2016.04.120.

(7) Tahar RBH, Ban T, Ohya Y, Takahashi Y. Optical, structural, and electrical properties of indium oxide thin films prepared by the sol-gel method. J Appl Phys 1997;82:865-70. https://doi.org/10.1063/1.365786.

(8) Yeom HI, Ko JB, Mun G, Park SHK. High mobility polycrystalline indium oxide thin-film transistors by means of plasma-enhanced atomic layer deposition. J Mater Chem C 2016;4:6873-80. https://doi.org/10.1039/C6TC00580B.

(9) Mane AU, Allen AJ, Kanjolia RK, Elam JW. Indium Oxide Thin Films by Atomic Layer Deposition Using Trimethylindium and Ozone. J Phys Chem C 2016;120:9874-83. https://doi.org/10.1021/ACS.JPCC.6B02657.

(10) Zhang F, Sun G, Zheng L, Liu S, Liu B, Dong L, et al. Interfacial study and energy-band alignment of annealed Al2O3 films prepared by atomic layer deposition on 4H-SiC. J Appl Phys 2013;113:44112. https://doi.org/10.1063/1.4789380.

(11) Bouabibsa I, Lamri S, Sanchette F. Structure, Mechanical and Tribological Properties of Me-Doped Diamond-Like Carbon (DLC) $(\mathrm{Me}=\mathrm{Al}, \mathrm{Ti}$, or $\mathrm{Nb})$ Hydrogenated Amorphous Carbon Coatings. Coatings 2018, Vol 8, Page 370 2018;8:370. https://doi.org/10.3390/COATINGS8100370.

(12) Xiang J, Ding Y, Du L, Xu C, Li T, Wang X, et al. Investigation of N Type Metal TiAlC by Thermal Atomic Layer Deposition Using TiCl 4 and TEA as Precursors. ECS J Solid State Sci Technol 2016;5:P299-303. https://doi.org/10.1149/2.0291605jss.

(13) Xiang J, Ding Y, Du L, Li J, Wang W, Zhao C. Growth mechanism of atomic-layer-deposited TiAlC metal gate based on TiCl4 and TMA precursors. Chinese Phys B 2016;25. https://doi.org/10.1088/16741056/25/3/037308. 

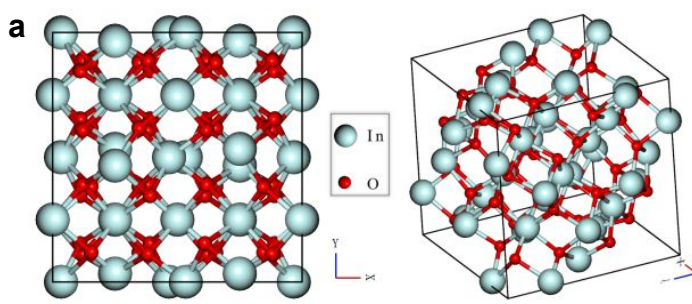

b

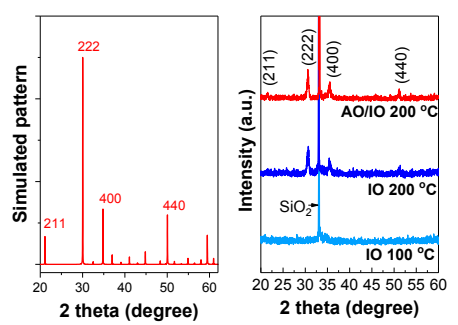

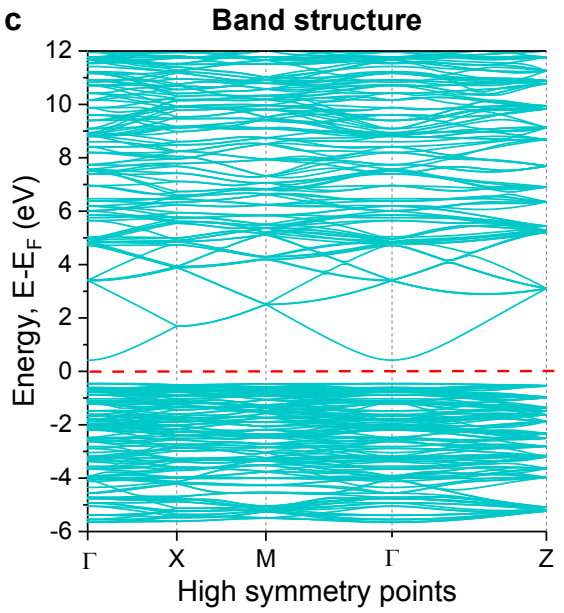

Density of states

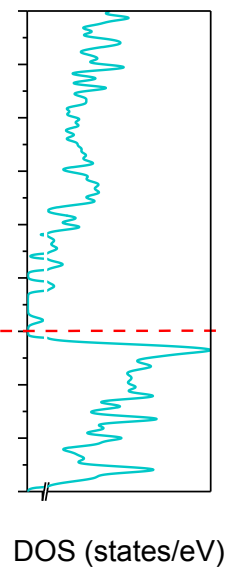

Figure S3. DFT simulation of $\mathrm{In}_{2} \mathrm{O}_{3}$. (a) A cubic supercell model of $\operatorname{In}_{2} \mathrm{O}_{3}$ (with 32 In and $48 \mathrm{O}$ atoms; lattice constant $=10.2996$ angstroms) obtained at materialsproject.org $/$ materials $/ \mathrm{mp}-22598$. (b) Simulated diffraction pattern of the $\mathrm{In}_{2} \mathrm{O}_{3}$ model compared to the XRD data of IO (Figure 1e) for confirming the validity of this model. (c) Electronic band structure and density of states of the $\mathrm{In}_{2} \mathrm{O}_{3}$ model obtained by DFT calculations, showing (i) the n-type property of the $\operatorname{In}_{2} \mathrm{O}_{3}$ since the Fermi level (red-dash line) is closer to the conduction band, and (ii) a narrow bandgap of $\operatorname{In}_{2} \mathrm{O}_{3}$ (ca. $0.95 \mathrm{eV}$ ) consistent with the reference data at materialsproject.org/materials/mp-22598.

Here, the diffraction pattern of the model was simulated using VESTA (ver 3.4.8, with the source radiation of $1.54059 \AA) .{ }^{1}$ The main peaks in the simulated diffraction pattern and the XRD result are located at almost the same $2 \theta$ values, indicating that this model can be used and analyzed for further understandings of our IO sample's properties. The DFT calculations were perfomed via BURAI (ver. 1.3) - a graphical user interface of Quantum Espresso. ${ }^{2-4}$ In this study, we used the DFT method based on plane waves and pseudopotentials, as implemented in the Quantum Espresso package. The Perdew-Burke-Ernzerh (PBE) functional was chosen to approximate the exchange correlation energy functional. ${ }^{5}$

\section{References}

(1) K. Momma and F. Izumi. VESTA 3 for three-dimensional visualization of crystal, volumetric and morphology data, J. Appl. Crystallogr. (2011) 44, p. 1272-1276.

https://doi.org/10.1107/S0021889811038970.

(2) S. Nishihara. BURAI - A GUI of Quantum ESPRESSO. https://nisihara.wixsite.com/burai (accessed July 30, 2021).

(3) P. Giannozzi, S. Baroni, N. Bonini, M. Calandra, R. Car, C. Cavazzoni, D. Ceresoli, G.L. Chiarotti, M. Cococcioni, I. Dabo, et al. QUANTUM ESPRESSO: A modular and open-source software project for quantum simulations of materials, J. Phys. Condens. Matter. (2009) 21, p. 395502. https://doi.org/10.1088/0953-8984/21/39/395502.

(4) P. Giannozzi, O. Baseggio, P. Bonfà, D. Brunato, R. Car, I. Carnimeo, C. Cavazzoni, S. de Gironcoli, P. Delugas, F.F. Ruffino, et al. Quantum ESPRESSO toward the exascale, J. Chem. Phys. (2020) 152, p. 154105. https://doi.org/10.1063/5.0005082.

(5) J. Harrell, M. Acikgoz, H. Lieber Sasson, I. Visoly-Fisher, A. Genova, M. Pavanello. Models of Surface Morphology and Electronic Structure of Indium Oxide and Indium Tin Oxide for Several Surface Hydroxylation Levels, J. Phys. Chem. C. (2018) 122, p. 584-595. https://doi.org/10.1021/acs.jpcc.7b10267. 

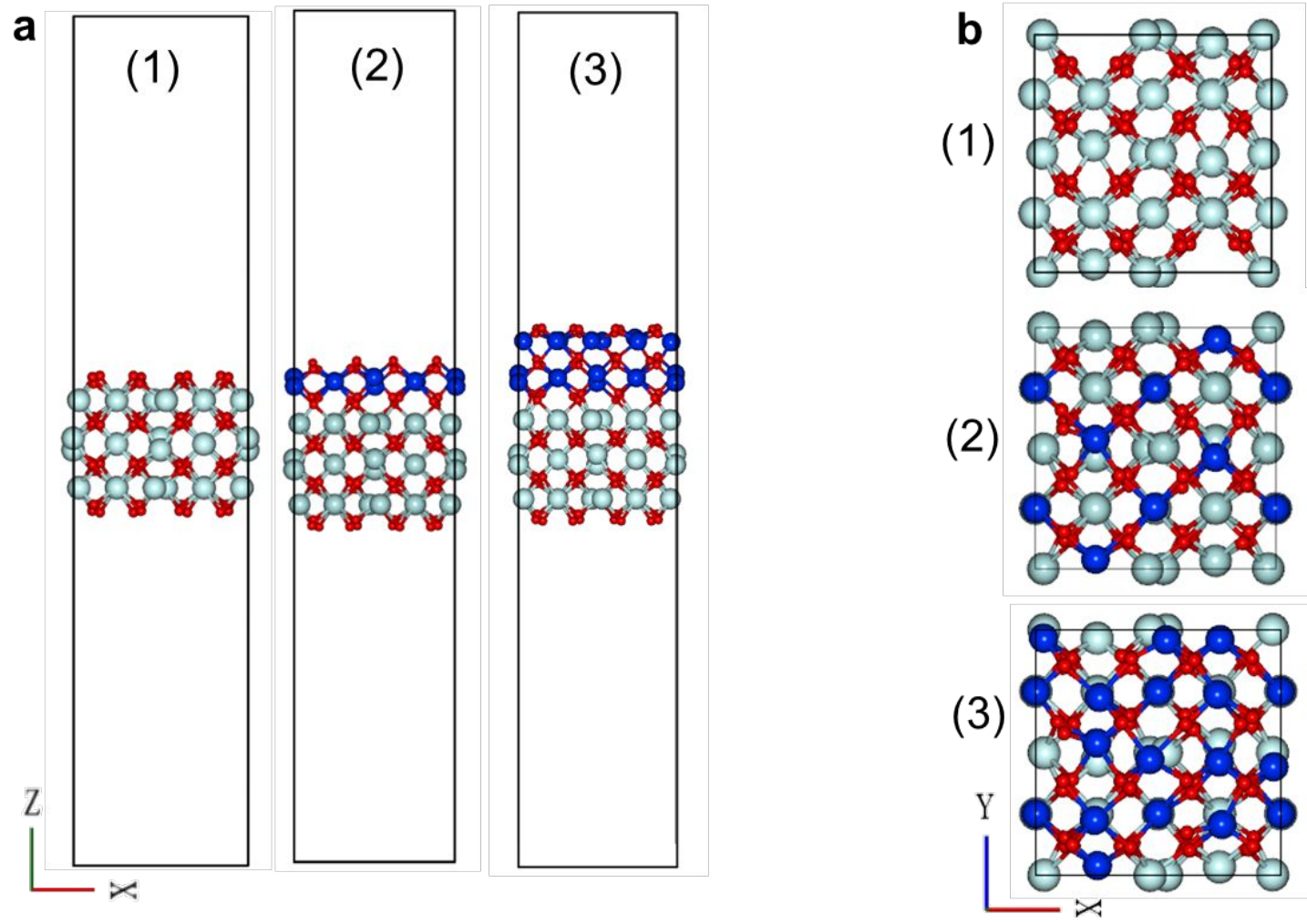

Figure S4. Modelling the $\mathrm{In}_{2} \mathrm{O}_{3}$ layer and the $\mathrm{Al}_{2} \mathrm{O}_{3} / \mathrm{In}_{2} \mathrm{O}_{3}$ interface. (a1, b1) Slab model of IO, which is based on the (100) direction of the $\mathrm{In}_{2} \mathrm{O}_{3}$ cubic supercell; the images were captured from the $\mathrm{X}-\mathrm{Z}$ and $\mathrm{X}-\mathrm{Y}$ planes (front view and top view), respectively. (a2, b2) Slab model of 1-AO/IO, in which one layer of AO was added on the top of the IO (100) slab. (a3, b3) Slab model of 2$\mathrm{AO} / \mathrm{IO}$, which have two layers of $\mathrm{AO}$ on the $\mathrm{IO}(100)$ slab. Here, the 1-AO/IO and 2-AO/IO slabs represent the $\mathrm{AO} / \mathrm{IO}$ interface. Here, $\mathrm{O}$, In, and $\mathrm{Al}$ atoms are presented in red, light cyan, and dark blue colors, respectively.

Because the XPS data in Supporting Figure S2e indicated the dominant portion of $\mathrm{InO}_{\mathrm{x}}$ in the IO layer, we selected the (100) direction of the $\mathrm{In}_{2} \mathrm{O}_{3}$ cubic supercell for building the IO slab, where there exists $24 \mathrm{In}$ and $48 \mathrm{O}$ atoms within the periodic boundary conditions with two 20 -angstron vacuum regions in Z-direction; it is matched to the stoicheometry of highly electroconducting $\mathrm{InO}_{2}$. Since the loading of AO is small and AO is amorphous as revealed in XPS and XRD measurements, the coordinates of $\mathrm{Al}$ and $\mathrm{O}$ atoms of $\mathrm{AO}$ were modeled following those of In and $\mathrm{O}$ atoms. The 1-AO/IO slab contains $8 \mathrm{Al}$ plus $24 \mathrm{In}$ and $59 \mathrm{O}$ atoms while the $2-\mathrm{AO} / \mathrm{IO}$ slab contains $16 \mathrm{Al}$ with $24 \mathrm{In}$ and $72 \mathrm{O}$ atoms. These slabs were constructed using BURAI and then optimized with the default number of stored charges $=8$ and a converged $500 \mathrm{eV}$ plane wave cut-off (convergence threshold $=5.10^{-3}$ Ry or $0.068 \mathrm{eV}$ ). 

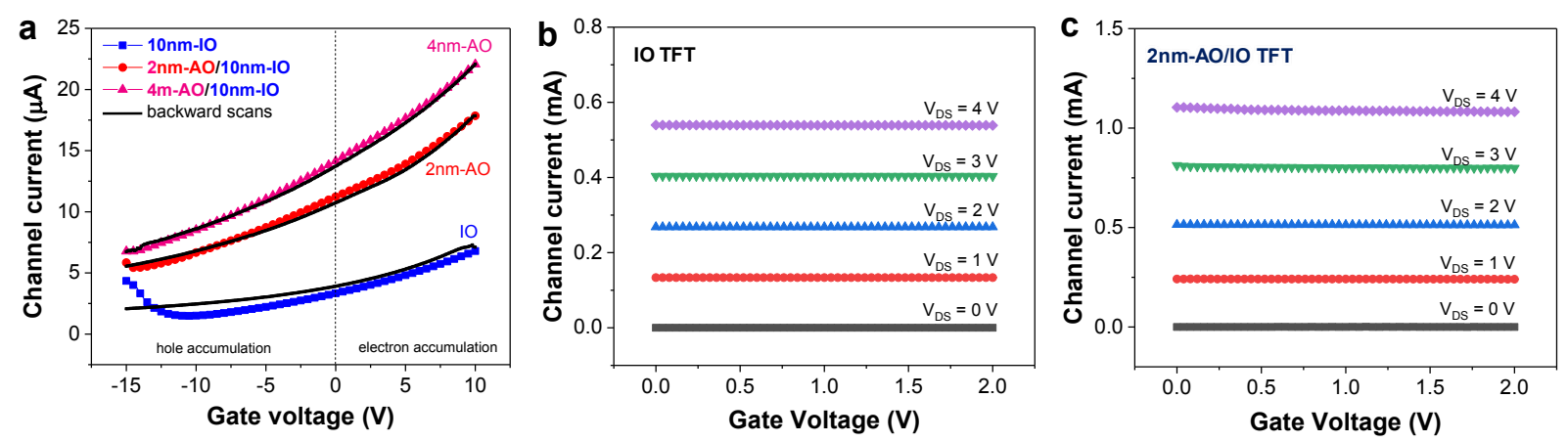

Figure S5. TFT characteristics. (a) Charge transfer characteristics of IO and AO/IO TFT devices (patterned) measured under a fixed drain bias $(\mathrm{VDS}=0.01 \mathrm{~V})$, indicating their electron-rich property. (b,c) Output characteristics of IO and AO/IO TFT devices, respectively, showing their high electrical conductance at various drain voltages $(\mathrm{VDS}=0 \sim 4 \mathrm{~V})$. 

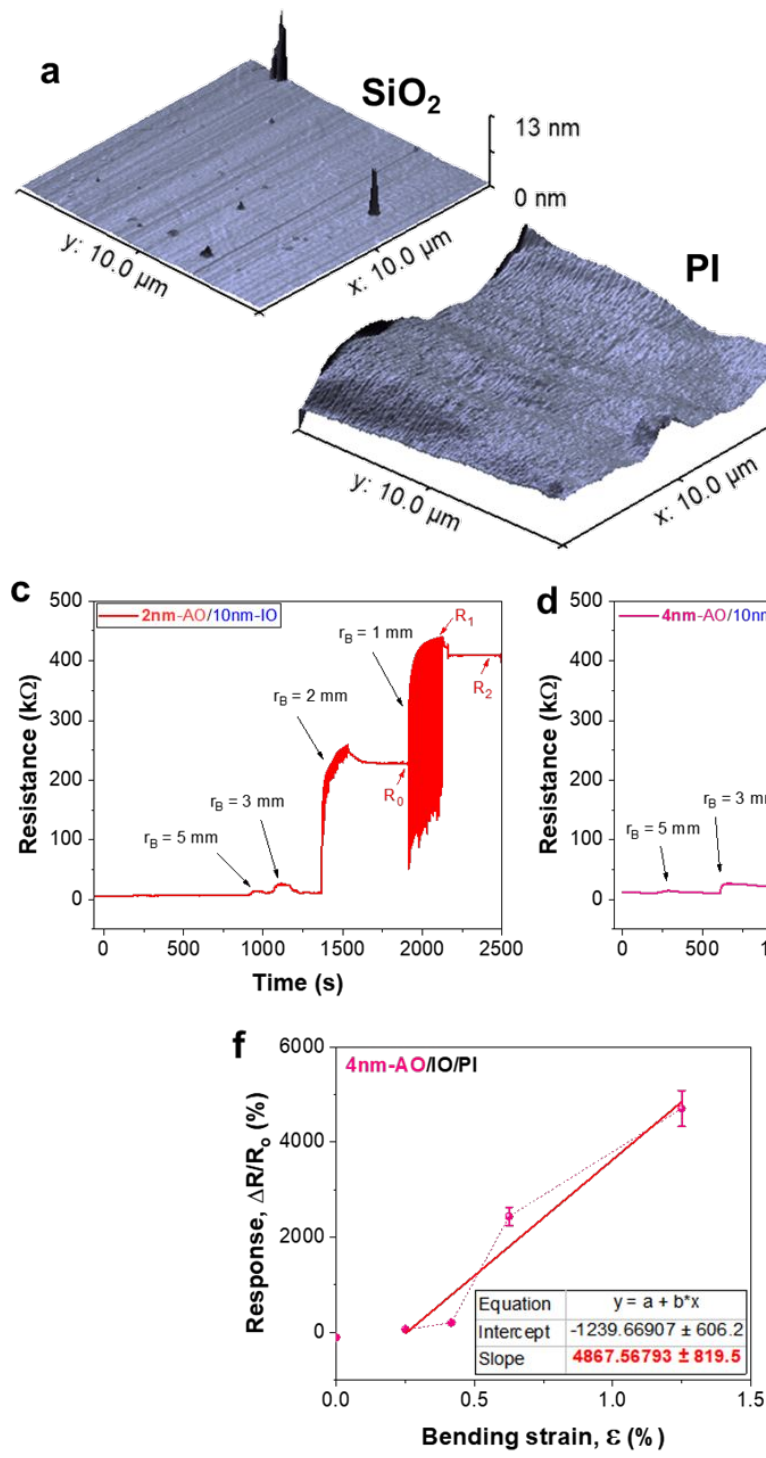

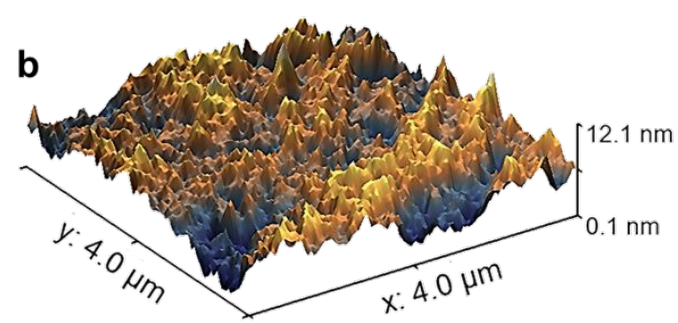

$9.2 \mathrm{~nm}$
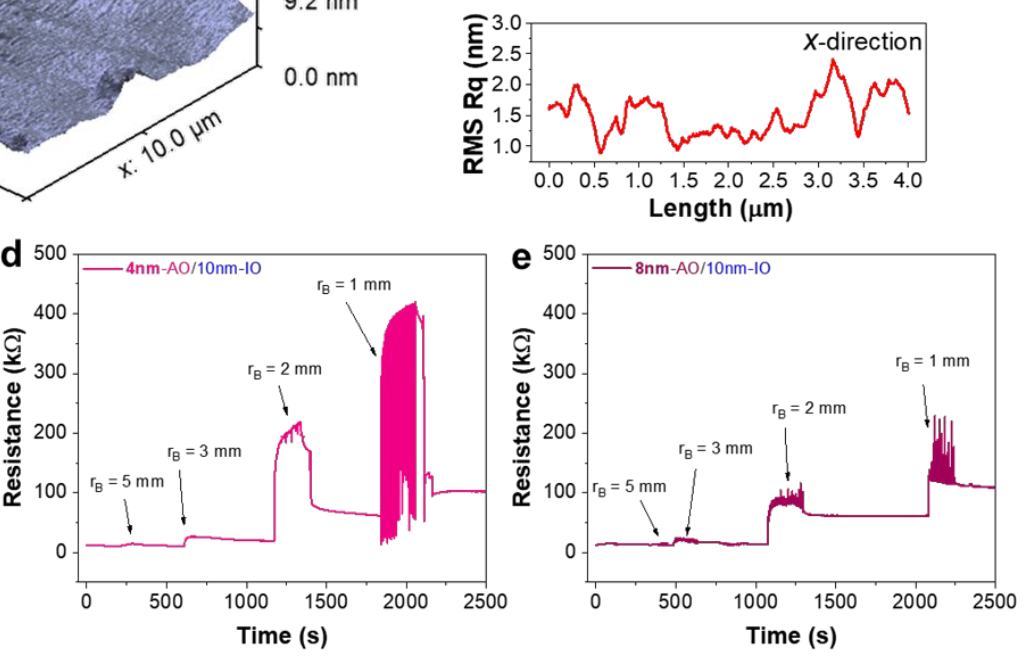

g

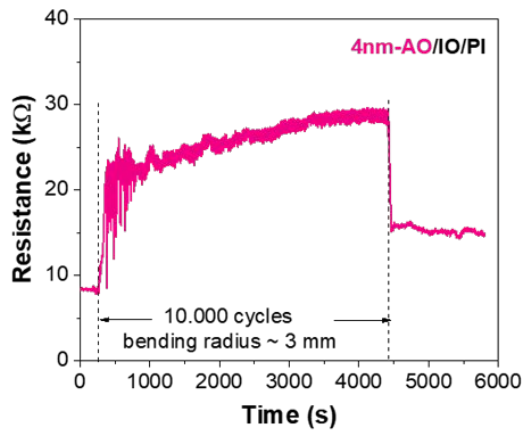

Figure S6. Cyclic bending measurements. (a) AFM images of $\mathrm{SiO}_{2}$ and PI substrates. (b) AFM imange and roughness profile (RMS Rq) of $4 \mathrm{~nm}-\mathrm{AO} / 10 \mathrm{~nm}-\mathrm{IO} / \mathrm{PI}$, showing its high roughness (ca. $2 \mathrm{~nm}$ ). (c-e) Changes in resistance of flexible samples with AO thickness of 2, 4, and $8 \mathrm{~nm}$, respectively, under various bending radii $(5 \sim 1 \mathrm{~mm})$; here, 100 cycles were applied at each bending radius and sampling rate was fixed at $0.5 \mathrm{~s}$ per point. (g) Strain response and gauge factor of $4 \mathrm{~nm}-$ $\mathrm{AO} / 10 \mathrm{~nm}-\mathrm{IO}$ strain sensor. Here, bending strain $(\varepsilon)$ was estimated following the equation: $\varepsilon \approx d / 2$ $r_{B}$ where $d$ is the sample thickness (including the PI substrate), and $r_{B}$ is bending radius. ${ }^{1}$ Gauge factor was obtained ca. $4860 \pm 820$. (f) Sustainability of our flexible sample after 10.000 bending cycles at $r_{B}$ of $3 \mathrm{~mm}$.

\section{References:}

(1) Trung, T. Q.; Tien, N. T.; Kim, D.; Jang, M.; Yoon, O. J.; Lee, N.-E. A Flexible Reduced Graphene Oxide Field-Effect Transistor for Ultrasensitive Strain Sensing. Adv. Funct. Mater. 2014, 24 (1), 117-124. https://doi.org/10.1002/adfm.201301845. 
Table S1. Comparison of some strain sensors.

\begin{tabular}{ccccc}
\hline Sensitive material & Deposition method & Gauge factor & Strain (\%) & Ref. \\
\hline GWFs (/PDMS) & Casting & 10000 & $\sim 30$ & 1 \\
Graphene (/PDMS) & Casting & 14 & $\sim 7.1$ & 2 \\
Polyurethane/Carbon Black Fibrous & Casting & 8960 & $\sim 160$ & 3 \\
Si rubber (/PDMS) & Molding & 166.6 & $\sim 0.7$ & 4 \\
Carbon black (/paper) & Filtration & 4.3 & $\sim 0.6$ & 5 \\
CB/CNT (/paper) & Dipping & 73 & $\sim 0.25$ & 6 \\
4nm-AO/IO (/PI) & ALD & 4860 & $\sim 1.25$ & Here \\
\hline
\end{tabular}

\section{References:}

(1) Zhao, S.; Zheng, P.; Liu, Q.; Niu, L.; Cong, H.; Wan, A. Highly Stretchable Strain Sensor with Tunable Sensitivity via Polydopamine Template-Assisted Dual-Mode Cooperative Conductive Network for Human Motion Detection. Mater. Des. 2021, 206, 109780. https://doi.org/10.1016/J.MATDES.2021.109780.

(2) Wang, Y.; Wang, L.; Yang, T.; Li, X.; Zang, X.; Zhu, M.; Wang, K.; Wu, D.; Zhu, H. Wearable and Highly Sensitive Graphene Strain Sensors for Human Motion Monitoring. Adv. Funct. Mater. 2014, 24 (29), 46664670. https://doi.org/10.1002/ADFM.201400379.

(3) Wang, X.; Liu, X.; Schubert, D. W. Highly Sensitive Ultrathin Flexible Thermoplastic Polyurethane/Carbon Black Fibrous Film Strain Sensor with Adjustable Scaffold Networks. Nano-Micro Lett. 2021, 13 (1), 1-19. https://doi.org/10.1007/S40820-021-00592-9/FIGURES/9.

(4) Kim, D. S.; Choi, Y. W.; Shanmugasundaram, A.; Jeong, Y. J.; Park, J.; Oyunbaatar, N. E.; Kim, E. S.; Choi, M.; Lee, D. W. Highly Durable Crack Sensor Integrated with Silicone Rubber Cantilever for Measuring Cardiac Contractility. Nat. Commun. 2020111 2020, 11 (1), 1-13. https://doi.org/10.1038/s41467-019-14019-y.

(5) Liu, H.; Jiang, H.; Du, F.; Zhang, D.; Li, Z.; Zhou, H. Flexible and Degradable Paper-Based Strain Sensor with Low Cost. ACS Sustain. Chem. Eng. 2017, 5 (11), 10538-10543. https://doi.org/10.1021/ACSSUSCHEMENG.7B02540/SUPPL_FILE/SC7B02540_SI_003.AVI.

(6) Li, Q.; Liu, H.; Zhang, S.; Zhang, D.; Liu, X.; He, Y.; Mi, L.; Zhang, J.; Liu, C.; Shen, C.; Guo, Z. Superhydrophobic Electrically Conductive Paper for Ultrasensitive Strain Sensor with Excellent Anticorrosion and Self-Cleaning Property. ACS Appl. Mater. Interfaces 2019, 11 (24), 21904-21914. https://doi.org/10.1021/ACSAMI.9B03421. 

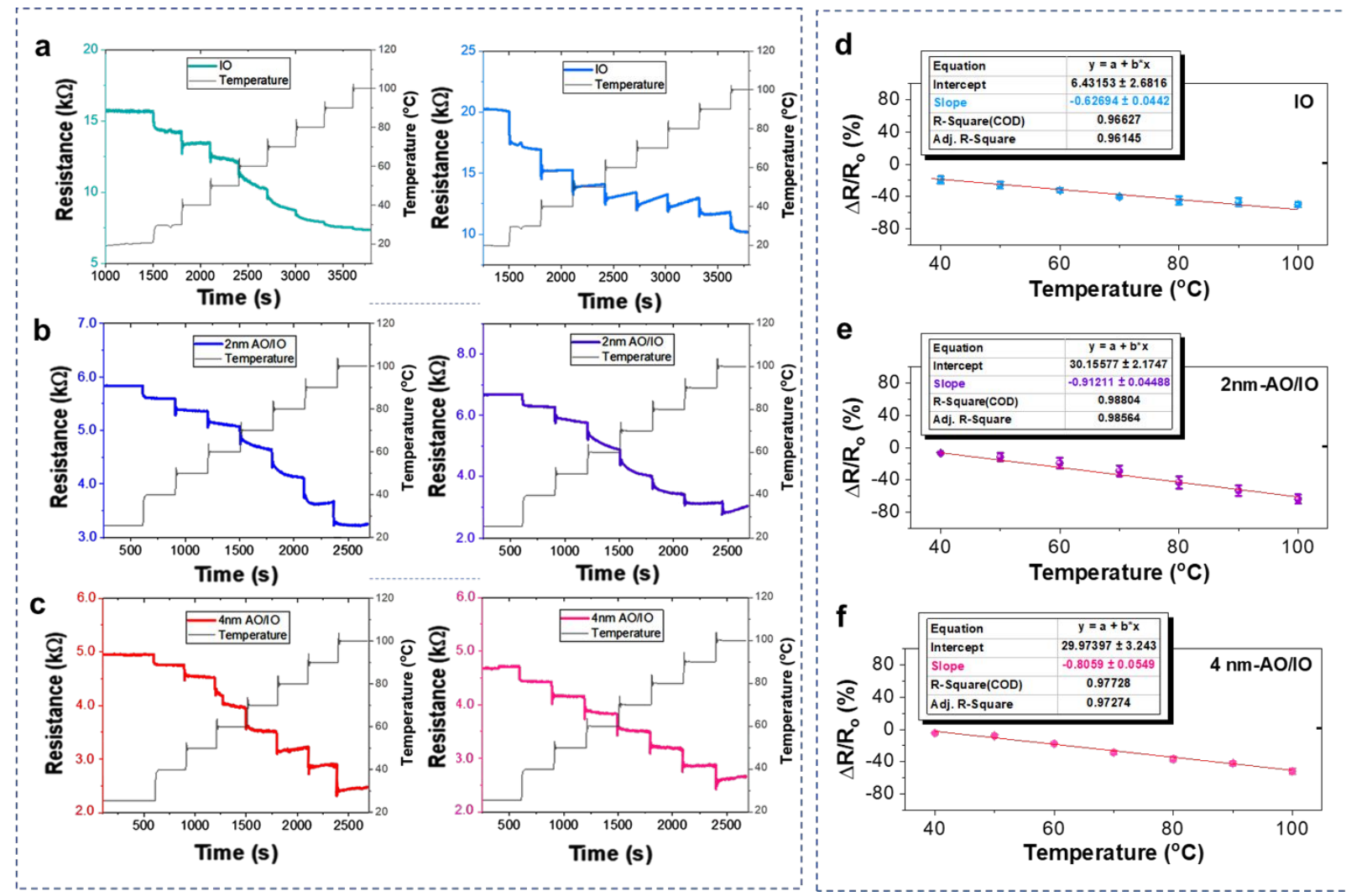

Figure S7. Temperature responses in an oxygen flow. (a-c) Temperature-dependent resistance changes of IO, 2nm-AO/IO, and 4nm-AO/IO films, respectively, placed in a closed chamber with a 500 -sccm flow of $21 \% \mathrm{O}_{2} / \mathrm{N}_{2}$ for investigating the oxidation effect at high temperatures. Each sample was tested two times, and three plots on the left side were obtained before the ones on the right side. (d-f) Linear fitting of the response-vs-temperature plots of those films, respectively, to extract their temperature sensitivity.

Here, the sample resistance decreased under heating. As observed Figure S7a-c, the IO and 2nm$\mathrm{AO} / \mathrm{IO}$ samples were affected by the oxygen flow (further oxidation) after the first test, particularly at $80-100{ }^{\circ} \mathrm{C}$ where the sample resistance started to increase. During the second test, that phenomenon was observed more clearly. Among three samples, $4 \mathrm{~nm}-\mathrm{AO} / \mathrm{IO}$ was affected the most slightly. The average temperature sensitivity was $0.63 \%{ }^{\circ} \mathrm{C}^{-1}$ for $\mathrm{IO}, 0.91 \%{ }^{\circ} \mathrm{C}^{-1}$ for $2 \mathrm{~nm}-\mathrm{AO} / \mathrm{IO}$, and $0.81 \%{ }^{\circ} \mathrm{C}^{-1}$ for $4 \mathrm{~nm}-\mathrm{AO} / \mathrm{IO}$. Although these values are not as high as the one in Figure 4 , these results confirmed the protection role of $\mathrm{AO}$, which led to the better temperature sensitivity of $\mathrm{AO} / \mathrm{IO}$ layers than that of the IO layer. 
Table S2. Comparison of some flexible temperature sensors.

\begin{tabular}{ccccccc}
\hline Sensitive material & $\begin{array}{c}\text { Deposition } \\
\text { sethod }\end{array}$ & $\begin{array}{c}\text { Sensitivity } \\
\left(\%{ }^{\circ} \mathbf{C}^{-1}\right)\end{array}$ & $\begin{array}{c}\text { Response } \\
\text { Time }(\mathbf{s})\end{array}$ & $\begin{array}{c}\text { Mesurement } \\
\text { range }\left({ }^{\circ} \mathbf{C}\right)\end{array}$ & $\begin{array}{c}\text { Resolution } \\
\left({ }^{\circ} \mathbf{C}\right)\end{array}$ & Ref. \\
\hline RGO film (/PET) & Air-spray & 0.6345 & 1.2 & $30-100$ & 5 & 1 \\
RGO filled cellulose film & Solution coating & - & - & $25 \sim 80$ & 3 & 2 \\
CNT /PEDOT:PSS (/PET) & Printing & 0.25 & $1 \sim 2$ & $21 \sim 80$ & - & 3 \\
Silver ink (/PI) & Printing & 0.22 & 0.1 & $20 \sim 60$ & - & 4 \\
$\mathrm{Al}_{2} \mathrm{O}_{3} / \mathrm{In}_{2} \mathrm{O}_{3}$ (/PI) & $\mathrm{ALD}$ & $0.81 \sim 1$ & $2 \sim 3$ & $25 \sim 100$ & 0.1 & Here \\
\hline
\end{tabular}

\section{References:}

(1) Liu, G.; Tan, Q.; Kou, H.; Zhang, L.; Wang, J.; Lv, W.; Dong, H.; Xiong, J. A Flexible Temperature Sensor Based on Reduced Graphene Oxide for Robot Skin Used in Internet of Things. Sensors (Switzerland) 2018, 18 (5). https://doi.org/10.3390/s18051400.

(2) Sadasivuni, K. K.; Kafy, A.; Kim, H. C.; Ko, H. U.; Mun, S.; Kim, J. Reduced Graphene Oxide Filled Cellulose Films for Flexible Temperature Sensor Application. Synth. Met. 2015, 206, 154-161.

https://doi.org/10.1016/j.synthmet.2015.05.018.

(3) Harada, S.; Kanao, K.; Yamamoto, Y.; Arie, T.; Akita, S.; Takei, K. Fully Printed Flexible Fingerprint-like Three-Axis Tactile and Slip Force and Temperature Sensors for Artificial Skin. ACS Nano 2014, 8 (12), 12851-12857. https://doi.org/10.1021/NN506293Y.

(4) Dankoco, M. D.; Tesfay, G. Y.; Benevent, E.; Bendahan, M. Temperature Sensor Realized by Inkjet Printing Process on Flexible Substrate. Mater. Sci. Eng. B 2016, 205, 1-5.

https://doi.org/10.1016/J.MSEB.2015.11.003. 

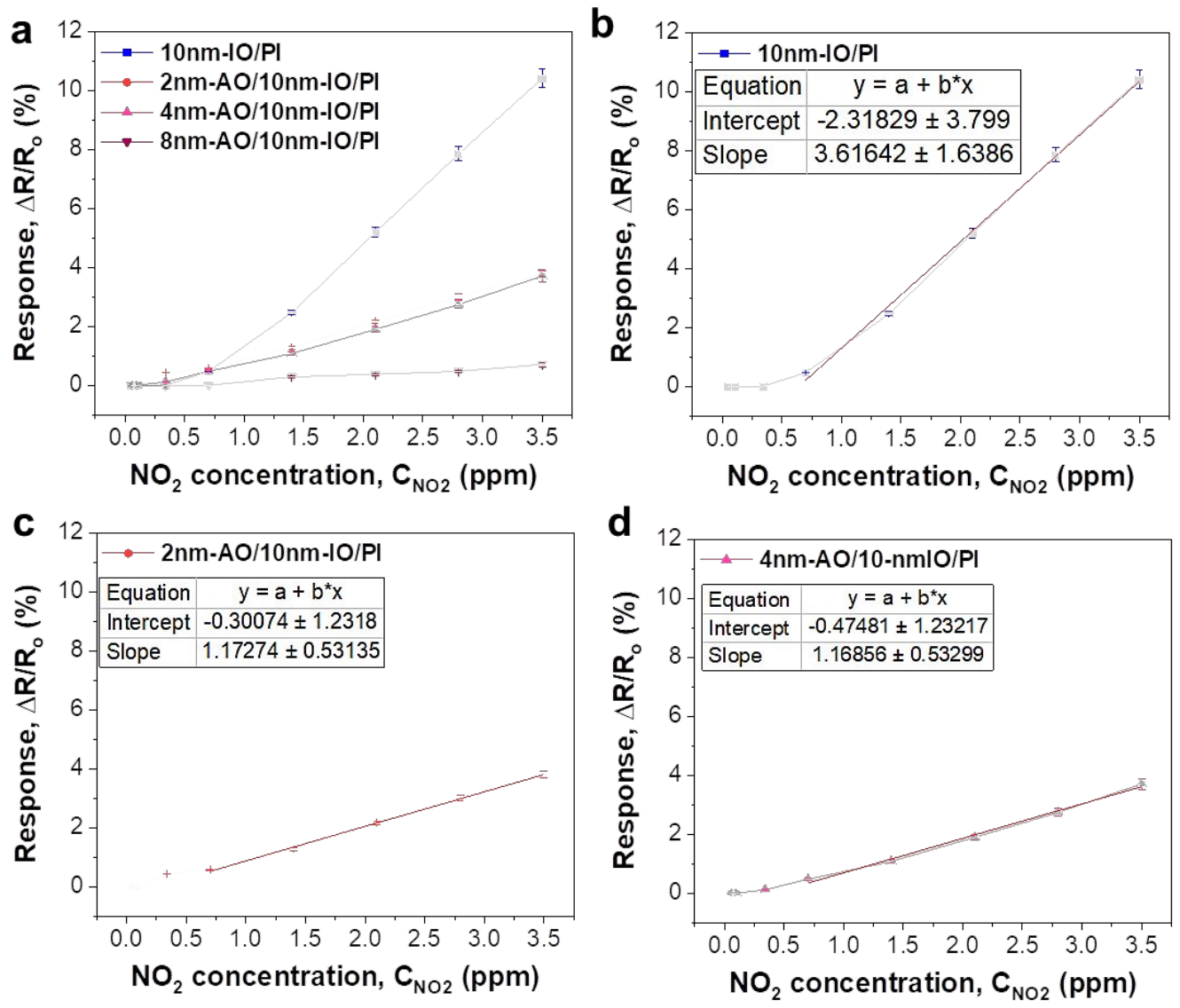

Figure S8. $\mathrm{NO}_{2}$ gas sensitivity. (a) Comparing responses of $\mathrm{IO}$ and $\mathrm{AO} / \mathrm{IO}$ devices as a function of $\mathrm{NO}_{2}$ concentration (extracted from Figure 5). (b,c,d) Linear fitting of the response-vs- $\mathrm{C}_{\mathrm{NO} 2}$ plots of those devices, excepting for $8 \mathrm{~nm}-\mathrm{AO} / 10 \mathrm{~nm}-\mathrm{IO}$ (almost no gas response), in other to find their sensitivity from the slope of the plots. 

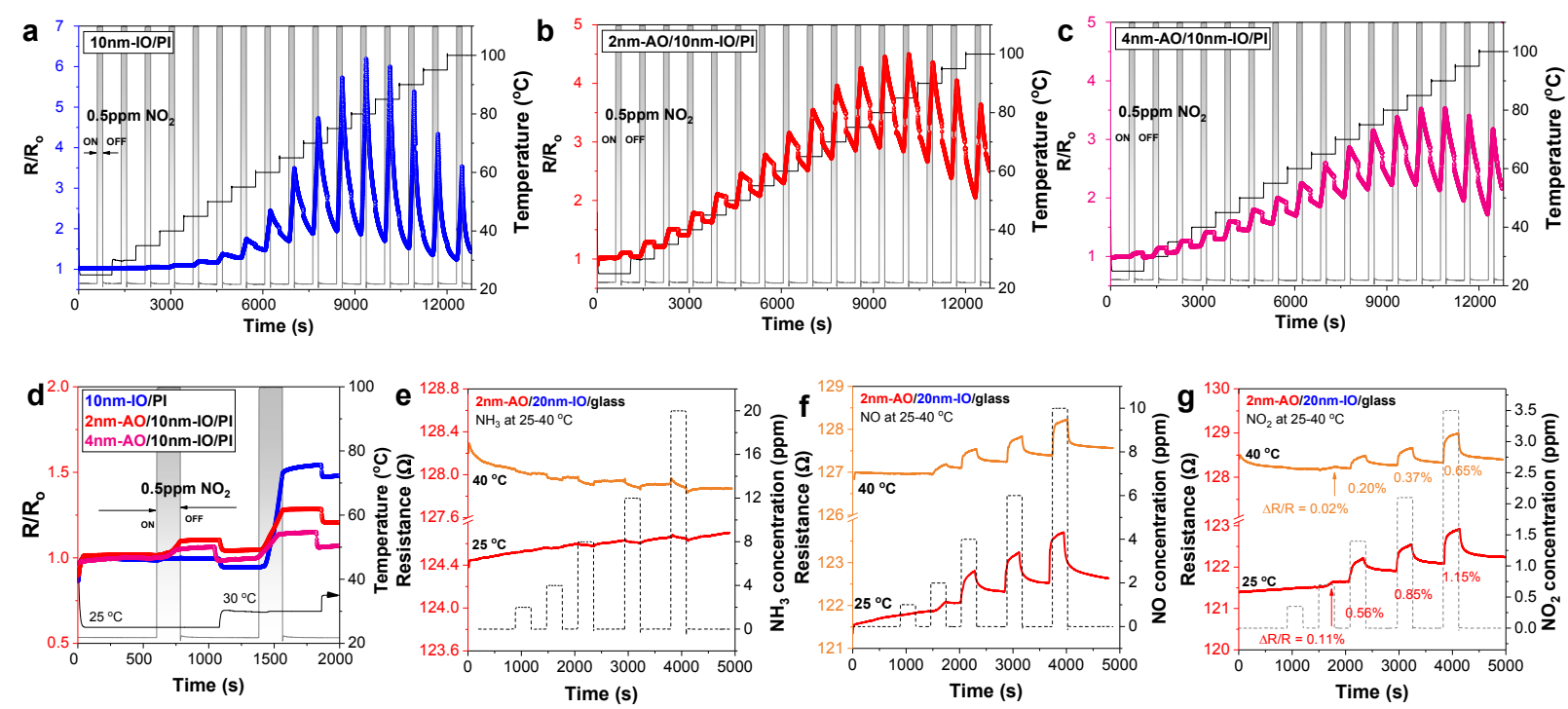

Figure S9. Operation temperature of gas sensor. (a-c) Cyclic $\mathrm{NO}_{2}$ exposures $(0.5 \mathrm{ppm})$ and gas responses of $\mathrm{IO}$ and $\mathrm{AO} / \mathrm{IO}$ resistors, respectively, at various temperatures $\left(0 \sim 100{ }^{\circ} \mathrm{C}\right)$. Here, exposure time is $2 \mathrm{~min}$ and purging time is $10 \mathrm{~min}$. (d) A closer look to the first $\mathrm{NO}_{2}$ exposures of those devices when temperature increased from 25 to 30 and $35^{\circ} \mathrm{C}$ in order to demonstrate our way to determine the optimum operation temperature. Here, the results in $(a, b, c)$ indicate that the optimum operation temperature is ca. $65 \sim 75{ }^{\circ} \mathrm{C}$ where both response and recovery are likely balanced, and especially this is a hint for a better sensing recovery of metallic-conducting samples. (e-g) Gas responses of a metallic conducting sample (at 25 and $40{ }^{\circ} \mathrm{C}$ ) towards $\mathrm{NH}_{3}, \mathrm{NO}$, and $\mathrm{NO}_{2}$, respectively. Here, the increased resistance of the device when the operation temperature increased indicate its metallic conducting behavior. Besides, the sensing recovery of this metallic conducting device is confirmed much better than that of semiconducting $\mathrm{AO} / \mathrm{IO}$ devices at low temperatures. 